\section{Analysis of Alicyclobacillus acidoterrestris spores from different sporulation media subjected to wet-heat}

\author{
Celenk Molva, Ayse Handan Baysal \\ Department of Food Engineering, Izmir \\ Institute of Technology, Turkey
}

\section{Abstract}

The presence of Alicyclobacillus acidoterrestris endospores in fruit juices is a significant problem for the juice industry since they are able to survive pasteurization subsequently leading to the spoilage. To evaluate the mechanism of wet-heat, structural damage and the leakages of intracellular materials of $A$. acidoterrestris DSM 3922 spores from different sporulation media was studied at $90^{\circ} \mathrm{C}(15-45$ min). For sporulation, Bacillus acidoterrestris agar, Bacillus acidocaldarius agar, potato dextrose agar and malt extract agar were used. Based on the scanning electron microscopy, loss of internal volume and structural integrity were observed following heating which were further confirmed by the leakages of intracellular components. The obtained results suggest that the inactivation of $A$. acidoterrestris DSM 3922 spores by wet-heat is associated with damage to the coat and inner membrane depending on the sporulation medium composition and heating time.

\section{Introduction}

Endospores are among the most resistant forms of living organisms that can survive wet and dry heat, high hydrostatic pressure, desiccation, UV radiation, $\gamma$-radiation and antimicrobials that rapidly inactivate vegetative cells. ${ }^{1,2}$ There are many extrinsic and intrinsic factors that contribute to spore resistance. These factors can be classified as spore coat, cortex peptidoglycans, $\alpha / \beta$-type small acid soluble proteins (SASPs), DNA repair, core mineralization, spore maturation, core water content, inner membrane permeability, chemical state, sporulation conditions (sporulation medium, sporulation temperature) and others. ${ }^{3}$

Alicyclobacillus acidoterrestris is a thermoacidophilic, non-pathogenic, rod-shaped spore-forming bacterium characterized by the presence of $\omega$-alicyclic fatty acids as the major lipid components in its membranes. ${ }^{4,5} \mathrm{~A}$. acidoterrestris may survive pasteurization and can cause the spoilage of fruit juices due to its spore forming ability and thermoacidophilic nature. ${ }^{6}$ The spoilage caused by this bacterium has been detected in many commercial fruit juices such as apple, orange, tomato, white grape, pear, and grapefruit. ${ }^{5}$ This organism has been suggested as the target to be used in the design of adequate pasteurization processes of acidic food products. ${ }^{7}$ Since it has been associated with several spoilage problems, most studies have been carried out to determine its heat resistance characteristics rather than other Alicyclobacillus species. ${ }^{8}$ For the fruit juice industry, it is important to determine resistance properties of $A$. acidoterrestris spores to prolong the shelf-life of commercial pasteurized fruit juices and juice products. Sporulation conditions are important for wetheat resistance. On the other hand, it is not taken into account in heat process calculations. ${ }^{1}$ The objectives of the present study were to determine the effects of wet-heat on $\mathrm{A}$. acidoterrestris DSM 3922 spores grown on different sporulation media by scanning electron microscopy and to analyze the leakages $\left(\mathrm{OD}_{260}\right.$ and $\mathrm{OD}_{280}$ values).

\section{Materials and Methods}

\section{Spore production}

A reference strain of $A$. acidoterrestris DSM 3922 was kindly provided by Karl Poralla (Deutsche Sammlung von Mikroorganismen und Zellkulturen's collection, Braunschweig, Germany). For sporulation, mineral containing media [Bacillus acidoterrestris agar (BATA, Merck) and Bacillus acidocaldarius agar (BAA) $]^{9}$ and nonmineral containing media [potato dextrose agar (PDA, BD Difco) and malt extract agar (MEA, Oxoid)] were used. Spore suspensions were prepared based on the protocol as previously described ${ }^{10}$ and stored at $-20^{\circ} \mathrm{C}$ for further use.

\section{Heat treatment}

A temperature-controlled water bath (PSelecta Precisdig) was used for the wet-heat treatments at $90^{\circ} \mathrm{C}$ for 15,30 , and $45 \mathrm{~min}$. Heat treatments were performed in sterile deionized water as previously described. ${ }^{10}$ Briefly, the spore stock suspension $\left(10^{6}-10^{7} \mathrm{CFU} / \mathrm{mL}\right)$ was centrifuged. After centrifugation, the pellet was resuspended in $1 \mathrm{~mL}$ of sterile deionized water, and then transferred to a screw-cap test tube $(160 \times 100 \mathrm{~mm}$ glass tube with an inside diameter of $16 \mathrm{~mm}$ ). Inoculated tubes were placed in the water bath adjusted to $90^{\circ} \mathrm{C}$. During treatments, a K-type thermocouple (Hanna instruments, Woonsocket, RI, USA) was placed in another tube containing $1 \mathrm{~mL}$ uninoculated sterile deionized water and used as a control. After the control reached $90^{\circ} \mathrm{C}$,
Correspondence: Celenk Molva, Department of Food Engineering, Izmir Institute of Technology, Urla, 35430, Turkey.

Tel.: +90.232.7506276 - Fax: +90.232 .7506196 .

E-mail: celenkmolva@gmail.com

Key words: Wet-heat; sporulation media; scanning electron microscopy; leakage.

Acknowledgments: the authors would like to thank to the members of the Center for Materials Research (IZTECH MAM) for SEM imaging.

Contributions: AHB was involved in designing the experiments, $\mathrm{CM}$ performed the experimental work; $\mathrm{CM}$ and $\mathrm{AHB}$ analyzed the results and wrote the manuscript.

Conflict of interests: the authors declare no potential conflict of interests.

Received for publication: 27 September 2015. Revision received: 23 October 2015.

Accepted for publication: 5 November 2015.

This work is licensed under a Creative Commons Attribution NonCommercial 3.0 License (CC BYNC 3.0).

(C) Copyright C. Molva and A.H. Baysal, 2015 Licensee PAGEPress, Italy

Microbiology Research 2015; 6:6219

doi:10.4081/mr.2015.6219

the viable spore counts were determined by plating directly or serially diluted aliquots in maximum recovery diluent (MRD, 0xoid) onto PDA in duplicates for each heating period. The plates were incubated at $43^{\circ} \mathrm{C}$ for $48 \mathrm{~h}$.

\section{Scanning electron microscopy}

After treatments, samples were cooled on ice, and then centrifuged (14,800 RPM for 10 min). Next, the spore pellets were suspended in sterile deionized water and the suspension was centrifuged again. This washing step was repeated three times. After that, the pellet was resuspended in sterile deionized water. Finally, the resultant suspension $(10 \mu \mathrm{L})$ was fixed onto clean glass slides and air-dried overnight for SEM. For SEM imaging, samples were coated with gold at a vacuum of 0.09 mbar, for $90 \mathrm{~s}$, at $15 \mathrm{kV}$, in argon gas at a power of $15 \mathrm{~mA}$ and examined with a scanning electron microscope (Phillips XL-30S FEG). At least, five images were taken for each spore suspension.

\section{Leakage of intracellular compo- nents}

Samples were taken at heating intervals and centrifuged at $4^{\circ} \mathrm{C}(14,800 \mathrm{RPM}$ for $10 \mathrm{~min})$ immediately. The supernatant was examined for leakages of nucleic acid and protein by measuring the absorbance values at 260 and $280 \mathrm{~nm}$, with a UV spectrophotometer (Cary 
100 Bio, Varian Inc., CA, USA). The untreated samples were autoclaved at $121^{\circ} \mathrm{C}$ for $20 \mathrm{~min}$ to determine the total leakage and used as positive control. ${ }^{11}$ The leakage (\%) of samples was calculated using equations below:

Leakage $_{\text {nucleic acid }}(\%)=\frac{O D_{260 \mathrm{~nm} \text { sample }}}{O D_{260 \mathrm{~nm} \text { control }}} \times 100$

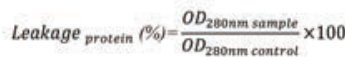

\section{Statistical analysis}

Data were measured in triplicates $(n=3)$ and expressed as means \pm standard deviations (Microsoft Excel 2003, Microsoft corp., USA). The Tukey-Kramer test was used to compare the means of treated groups $(\mathrm{P}<0.05)$ (Minitab 16, Minitab Inc., UK).

\section{Results and Discussion}

A. acidoterrestris spores exhibited approximately 1.2 to $1.5,2.7$ to 3.3 , and 3.1 to $3.7 \log$ reductions from the initial counts after 15,30 , and 45 min heating at $90{ }^{\circ} \mathrm{C}$, respectively in deionized water (Figure 1). There were significant differences among $\log$ reductions between all spore suspensions following heating 15 min and 45 min $(\mathrm{P}<0.05)$. On the other hand, no statistical difference was observed

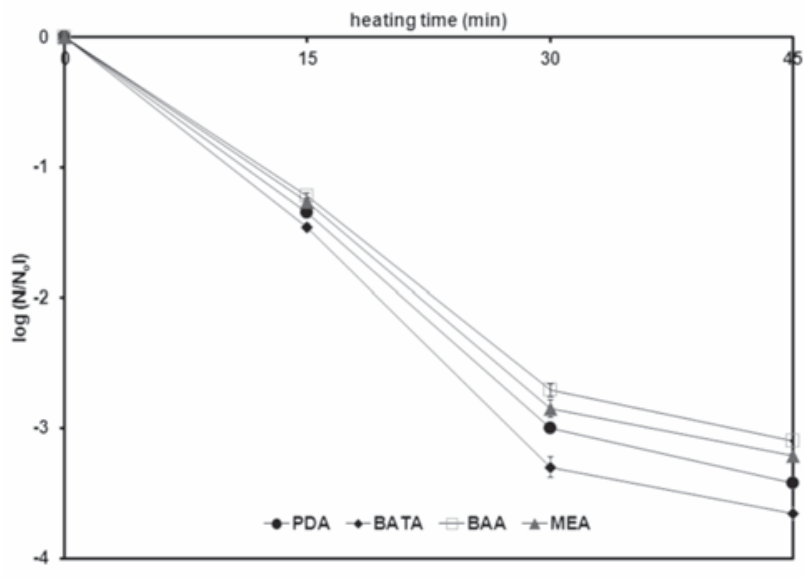

Figure 1. The logarithmic reductions of spores after wet-heat at $90^{\circ} \mathrm{C}$ for 15,30 and $45 \mathrm{~min}$. Data are presented as mean \pm standard deviation $(n=3)$.
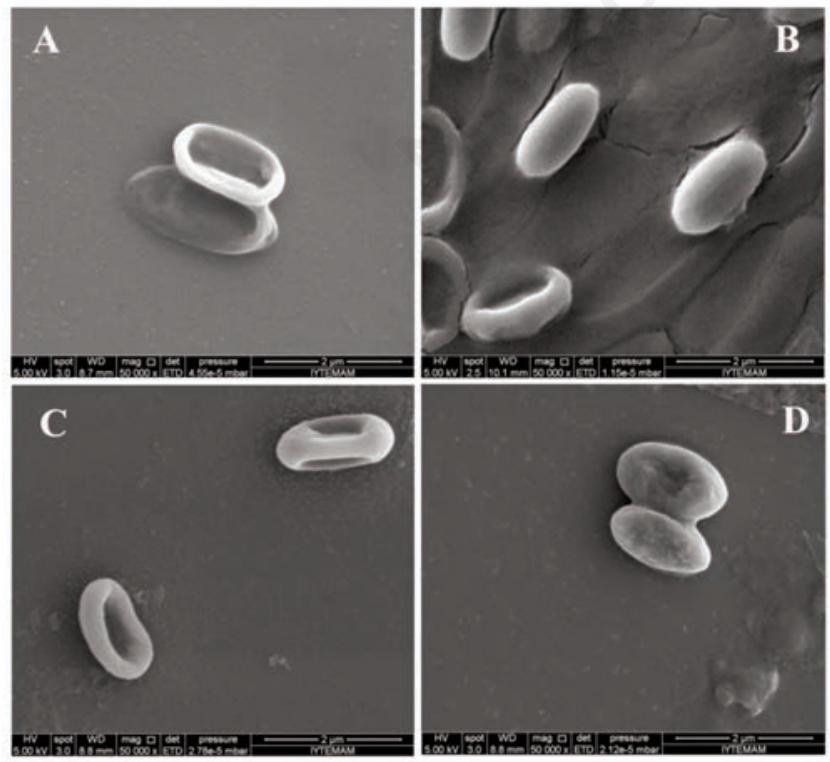

Figure 2. SEM images of untreated A. acidoterrestris spores (A) PDA, (B) MEA, (C) BATA, (D) BAA.

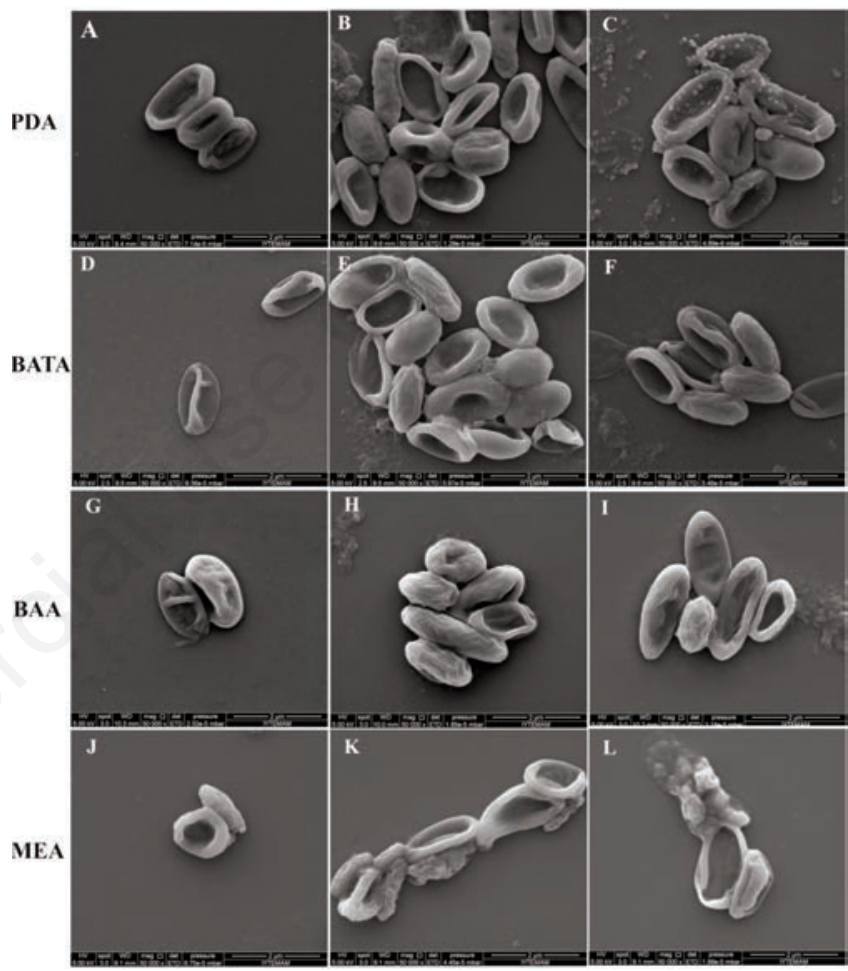

Figure 3. SEM images of A. acidoterrestris spores produced on PDA, BATA, BAA and MEA following wet-heat treatment for 15 $\min (A, D, G, J), 30 \mathrm{~min}(B, E, H, K)$, and $45 \mathrm{~min}(C, F, I, L)$.
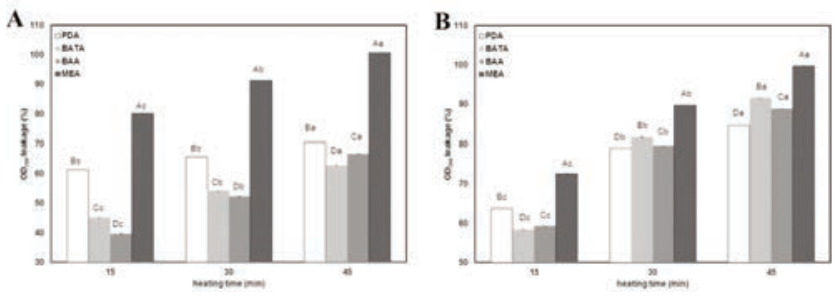

Figure 4. Leakages (\%) of (A) $\mathrm{OD}_{280}$ and (B) $\mathrm{OD}_{260}$ materials during wet-heat at $90^{\circ} \mathrm{C}$ for 15,30 and $45 \mathrm{~min}$. Data are presented as mean \pm standard deviation $(n=3)$. Within the same sampling time, values with different capital letters are significantly different $(P<0.05)$. Within the same spore suspension, values with different lower case are significantly different over time $(P<0.05)$. 
among spores obtained from PDA, BAA and MEA after 30 min $(P>0.05)$. Only, log reductions of spores produced on BATA were significantly different from other spore suspensions $(\mathrm{P}<0.05)$.

Representative SEM images showed that untreated spores are rod-shaped with rough (Figure 2A and $\mathrm{C}$ ) and smooth surfaces (Figure 2B and D) as previously reported. ${ }^{10}$ Treated spores indicated morphological changes depending on the heating time (Figure 3). Although most of the spores retained their structural integrity, a minority of the spores indicated very limited morphological changes such as destruction of inner structure (Figure $3 \mathrm{~A}$ ), crushed appearance (Figure 3D and G) and shrinkage (Figure 3J) after $15 \mathrm{~min}$. The loss of internal volume most probably due to the release of cellular components from the core and damage to the structural integrity is clearly visible following heating for 30 and $45 \mathrm{~min}$. As seen in Figure $3 \mathrm{C}$ and L, spores produced on nonmineral containing media lost some of its components. Following heating for $45 \mathrm{~min}, 3.42$ and 3.21 log inactivations were obtained among spores from PDA and MEA, respectively. Although similar reductions were observed among spores from BATA (3.66 $\log \mathrm{CFU} / \mathrm{mL})$ and BAA (3.1 $\log \mathrm{CFU} / \mathrm{mL})$, the SEM profiles from mineral containing media are different from nonmineral containing media at this time.

Similar to our findings, Mustafa et al. (2010) ${ }^{12}$ observed the destruction of the spore components of Bacillus cereus after fast heating and suggested that fast heating causes fast boiling of water and denatures proteins within endospores. Heat treatment primarily affects the germination process. ${ }^{13}$ Coleman et al. $(2007)^{14}$ also reported that moist-heat treated spores often appeared as injured. They supposed that some proteins can be damaged during wet-heat although this damage may only be conditionally lethal. According to the results of their study, they concluded that the inactivation was related to the ruptures of spore's inner membrane permeability barrier and damage to the core enzymes. In contrast, van Bokhorst-van de Veen et al. (2015) ${ }^{15}$ found that heat treatment at $95^{\circ} \mathrm{C}$ for 10 min caused no physical damage on the surface of $B$. cereus ATCC14579 spores compared to untreated ones.

Measurement of $\mathrm{OD}_{260}$ and $\mathrm{OD}_{280}$ values of the materials leaked out from the spores can be used to determine the changes on permeability of spore inner membrane due to the applied inactivation method. ${ }^{11}$ The leakages (\%) of $\mathrm{OD}_{280}$ (Figure $4 \mathrm{~A}$ ) and $\mathrm{OD}_{260}$ (Figure $4 \mathrm{~B}$ ) increased as the heating time increased.
There were significant differences between the treatments and $\mathrm{OD}_{280}$ values $(\mathrm{P}<0.05)$. Also, a strong correlation was found between the $0_{280}$ values (\%) and heating time $\left(\mathrm{R}^{2}>0.987\right)$. The leakages of $\mathrm{OD}_{280}$ materials were higher for spores from nonmineral containing media. And, a similar trend was obtained between spores produced on BATA and BAA. Interestingly, the leakage of $\mathrm{OD}_{280}$ materials from spores produced on MEA (100.7\%) was higher than that of autoclaved ones probably due to seriously damaged inner membrane after $45 \mathrm{~min}$ as previously reported for $B$. subtilis spores treated with the combination of high pressure-thermal sterilization and ethanol. ${ }^{11}$ The leakages of $\mathrm{OD}_{260}$ materials were higher for spores from nonmineral containing media after $15 \mathrm{~min}$. After $30 \mathrm{~min}$, the release of $\mathrm{OD}_{260}$ materials was approximately $79 \%, 82 \%, 80 \%$, and $90 \%$ among spores from PDA, BATA, BAA and MEA, respectively. The complete release (\%) was obtained from spores produced on MEA following $45 \mathrm{~min}$. In fact, the presence of proteins and nucleic acids in the spore suspensions indicated the damage to the spore coat and the release of core components due to the destruction of spore inner membrane following wet-heat ${ }^{16}$.

\section{Conclusions}

Based on the results, the release of both proteins and nucleic acids from both spores produced on mineral and nonmineral containing media might occur due to the disruption of the coat and inner membrane during wet-heat treatment under the tested conditions. On the other hand, the loss of internal volume and wrinkled appearance was obvious among heated spores from mineral containing media.

\section{References}

1. Carlin F. Origin of bacterial spores contaminating foods. Food Microbiol 2011;28:177-82.

2. Eijlander RT, Abee T, Kuipers OP. Bacterial spores in food: how phenotypic variability complicates prediction of spore properties and bacterial behavior. Curr Opin Biotechnol 2011;22:180-6.

3. Sella SRBR, Vandenberghe LPS, Soccol CR. Life cycle and spore resistance of spore-forming Bacillus atrophaeus. Microbiol Res 2014;169:931-9.
4. Hippchen B, Roll A, Poralla K. Occurrence in soil of thermo-acidophilic bacilli possessing $\omega$-cyclohexane fatty acids and hopanoids. Arch Microbiol 1981;129:53-5.

5. Silva FVM, Gibbs P. Alicyclobacillus acidoterrestris spores in fruit products and design of pasteurization processes. Trends Food Sci Technol 2001;12:68-74.

6. Torlak E. Efficacy of ozone against Alicyclobacillus acidoterrestris spores in apple juice. Int J Food Microbiol 2014; 172:1-4.

7. Silva FMS, Gibbs P, Vieira MC, Silva CLM. Thermal inactivation of Alicyclobacillus acidoterrestris under different temperature, soluble solids and $\mathrm{pH}$ conditions for the design of fruit processes. Int J Food Microbiol 1999;51:95-103.

8. Smit Y, Cameron M, Venter P, Witthuhn RC. Alicyclobacillus spoilage and isolation - A review. Food Microbiol 2011;28:331-49.

9. Darland G, Brock TD. Bacillus acidocaldarius sp.nov., an acidophilic thermophilic spore-forming bacterium. J Gen Microbiol 1971;67:9-15.

10. Molva C, Baysal AH. Effect of sporulation medium on wet-heat resistance and structure of Alicyclobacillus acidoterrestris DSM 3922-type strain spores and modeling of the inactivation kinetics in apple juice. Int J Food Microbiol 2014;189:82-8.

11. Zhang $Z$, Jiang $B$, Liao $X$ et al. Inactivation of Bacillus subtilis spores by combining high-pressure thermal sterilization and ethanol. Int J Food Microbiol 2012; 160: 99104.

12. Mustafa NEM, Keller U, Malkus U et al. Morphological changes induced by wetheat in Bacillus cereus endospores. Curr Res Bacteriol 2010;3:214-26.

13. Pandey R, Pieper GH, Beek AT et al. Quantifying the effect of sorbic acid, heat and combination of both on germination and outgrrowth of Bacillus subtilis spores at single cell resolution. Food Microbiol 2015;52:88-96.

14. Coleman WH, Chen D, Li YQ et al. How moist heat kills spores of Bacillus subtilis. J Bacteriol 2007;189:8458-66.

15. van-Bokhorst-van de Veen H, Xie H, Esveld $\mathrm{E}$ et al. Inactivation of chemical and heatresistant spores of Bacillus and Geobacillus by nitrogen cold atmospheric plasma evokes distinct changes in morphology and integrity of spores. Food Microbiol 2015;45:26-33.

16. Kim SY, Shin SJ, Song $\mathrm{CH}$ et al. Destruction of Bacillus licheniformis spores by microwave irradiation. J Appl Microbiol 2009;106:877-85. 